\title{
Applying a GIS based DRASTIC Model in the Assessment of Risk to Groundwater Resources Within the Underlying Aquifers in Part of Lagos State, Nigeria
}

\author{
Oladeji, O. S. \\ Department of Civil Engineering, Ladoke Akintola University of Technology, Ogbomoso, Nigeria. \\ Corresponding E-mail: osoladeji@lautech.edu.ng \\ DOI: 10.36108/laujoces/0202/40(0190)
}

\begin{abstract}
Lagos, Nigeria is one of the megacities in Africa with an estimated annual growth rate of 8\%, and its socio-economic growth has continually encouraged influx of people into the city. Hence, this has increased pressure on the underlying water resources with implications for public health and ecological related issues. In this study, anthropogenic induced risk posed to water resources within the underlying aquifers in part of Lagos State, Nigeria, was evaluated using qualitative DRASTIC modelling approach. Geo-hydrological data were acquired for site characterization and setting up of the model. The geology indicated multi-layered aquifer horizons, with extensive lateral lithological variations. The topography ranges between 1.5 and $60 \mathrm{~m}$ above mean sea level (amsl). The depth to groundwater is shallow, typically less than $1 \mathrm{~m}$ in the south, and a maximum depth of $20 \mathrm{~m}$ below ground level, in the north. A vulnerability map was developed from the cumulated sum of the DRASTIC index values. Anthropogenic activities within the study area were super-imposed on the vulnerability map to generate a risk map. The results show that 1\% of the study area is designated as High-Vulnerability-High-Risk area. Also, High-Vulnerability-Medium-Risk and Medium-Vulnerability-High-Risk constitute 3\% each of the area, while $16 \%$ and 25\% were designated as Medium-Vulnerability-Medium-Risk and Low-Vulnerability-Medium-Risk, respectively. Although, based on the DRASTIC input parameters, approximately 75\% of the area is designated as high and medium vulnerability, however absence of risk activities suggests no risk is posed to the underlying groundwater resource in approximately 52\% of this delineated subarea.
\end{abstract}

Keywords: DRASTIC, Groundwater, Anthropogenic, Vulnerability, Risk

\section{Introduction}

One of the major effects of global industrialization is urbanization, which consequently increases water demand (PRB, 2013), with implications for public health and ecology, as well as depletion of the underlying groundwater resources. Also, the apparent abundant occurrence of groundwater, and subsequently its excessive exploitation and increasing contamination (Oladeji and Elgy, 2013) from anthropogenic activities have further added additional pressure on the groundwater resource. Approximately $40-80 \%$ of deaths in developing nations occur due to infections from water related diseases (WHO 2010; Aderibigbe et al., 2008; Ayeni et al., 2011). Generally, groundwater is considered a preferred source compared to surface water because of its reliability, relative uniformity in its physical properties, and natural potability. These inherent valuable properties have made the resource to constitute an important source of water for public water supply, agricultural and industrial productions. Hence, qualitative and quantitative protection of the resource from derogation is imperative; otherwise its remediation is both technically difficult and financially expensive. According to Morris et al., (2003), approximately two billion people depend directly upon groundwater exploitation for domestic purpose, while about $40 \%$ of the global food production is directly supported by groundwater sourced irrigation programmes. In Nigeria population, approximately $48 \%$ depends on surface water for domestic use, $57 \%$ uses hand dug wells, $20 \%$ harvest rain, and $14 \%$ each have access to pipe borne and borehole water sources (FGN, 2007). 
The city of Lagos remains the industrial and commercial centre of Nigeria (Adelakun, 2009). Lagos is a megacity in Africa (Ilesanmi, 2010), with population and growth rate of approximately 21 million and 8\%, respectively (Akiyode, 2010). However, the rapid growth of the state and a dwindling finances of the nation have inflicted infrastructural neglect and setbacks (Ilesanmi, 2010), as well as posed major water management challenges (Akinyode, 2010), thus threatening the water security in the state. According to Grey and Sadoff (2007), water security is the availability of an acceptable quantity and quality of water for health, livelihoods, ecosystems and production, coupled with an acceptable level of water-related risk to the people, environment and economics.

The terms vulnerability and risk have been defined in the literature (Oladeji and Elgy, 2012). Vulnerability is defined as a measure of ease with which contaminant at the land surface reaches an aquifer, while risk is defined as the measure of the likelihood of occurrence of pollution, and the assessment of impact of such occurrence. Vulnerability can either be of specific type, where a particular contaminant is being considered or intrinsic which does not consider attributes or behaviour of any specific contaminant, but that of the aquifer materials. The available approaches used for mapping of groundwater vulnerability in the literature include EPIK technique (Doerfliger and Zwahlen, 1995), DRASTIC (Aller et al., 1987), SINTACS (Vrba and Zaporozec, 1994), and specific applications are based on the type and nature of the aquifer under study (El-Naqa, 2004; Pathak et al., 2009). Although, ranking index methods have associated drawbacks such as subjectivity in the choice of indices and weight assigned to the input parameters, however availability of the required input data in its implementation makes DRASTIC approach a preferred option as a reconnaissance and relative evaluation tool to delineate areas deserving a more detailed geo-hydrological evaluation. Therefore, the aim of this study is to evaluate the vulnerability and risk posed to groundwater resource within the underlying aquifers in part of Lagos State using qualitative approach.

\section{Material and Methods}

The study area occupies the central part of Lagos metropolis, and lies approximately between latitudes $6^{\circ} 23^{\prime}-6^{\circ} 42^{\prime} \mathrm{N}$ and longitudes $3^{\circ} 11^{\prime}-3^{\circ} 40^{\prime} \mathrm{E}$, with a total area of approximately 1095 $\mathrm{km}^{2}$ (Figure 1). Lagos state has been described as a zone of coastal creeks and lagoons, with relatively flat topographic relief, approximately 3 - $15 \mathrm{~m}$ amsl (Longe et al., 1987; Odumosu et al., 1999). The climate is tropical, characterized by wet and dry seasons, with annual average rainfall and temperature of $1,532 \mathrm{~mm}$ and $27^{\circ} \mathrm{C}$, respectively (Adepelumi et al., 2009). The vegetation is dominated by brackish and freshwater swamp (Aina et al., 1994; FEPA, 1998). Adepelumi et al., (2009) described the geology as largely underlain by Alluvia, characterized by sediments deposited under fluviate, lascustrine and marine environments. There is extensive lateral variation in lithology and hydraulic properties, forming a multi-layered aquifer system, separated by clayey horizons (Longe et al., 1987; Asiwaju-Bello and Oladeji, 2001).

\section{Conceptual framework}

In this study, the DRASTIC Index model approach (Aller et al., 1985) was adopted for evaluating groundwater vulnerability potential. The DRASTIC model is based on seven parametric layers namely depth to water, net recharge, aquifer media, soil media, topography, impact of vadose zone and hydraulic conductivity. Each DRASTIC parameter is assigned a relative weight between 1 and 5 , with 5 being considered most significant in regard to contamination potential and 1 being considered least significant. The corresponding field based measured geo-hydrologic data that underpins the seven layers used as input parameters for the DRASTIC model are static water level, rainfall intensity, geologic data, soil data, ground surface elevation, borehole logs and pumping test data. Static water levels were obtained from 50 borehole data while aquifer and soil media maps were prepared from the geology, well log data, topographical maps and soil map. Slope variation 
was extracted from the Digital Elevation Model (DEM) within the ArcGIS 10.1 software environment. The hydraulic conductivity values were obtained from the pumping test data. The acquired point geo-hydrologic data were converted into grid and subsequently interpolated using ArcGIS utility.

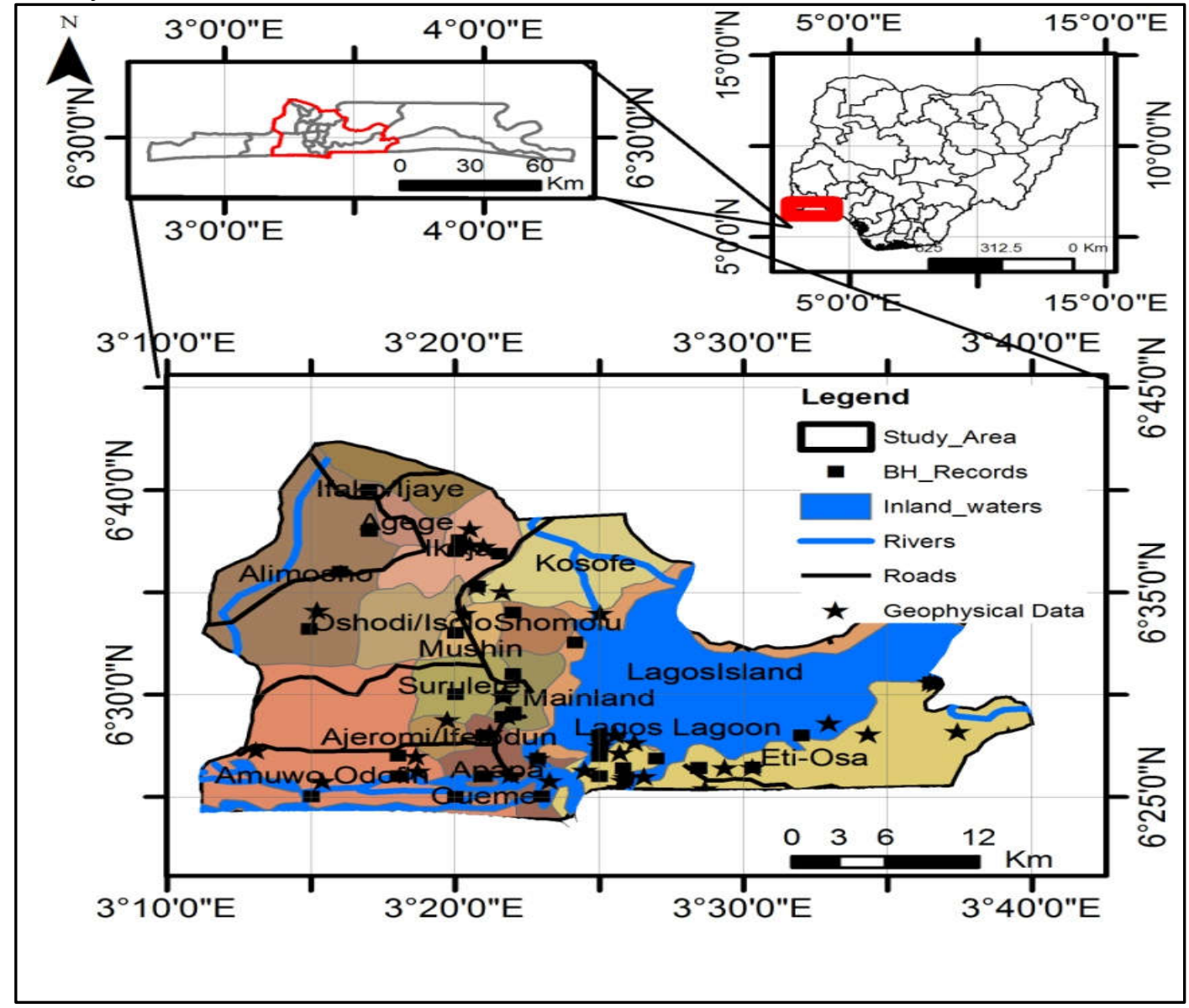

Figure 1: Description of the study area

The generated raster maps were subsequently reclassified into defined ranges of values or significant data types as contained in Table 1. Each parameter is assigned a rating and a weight multiplier indicating the relative influence of the parameter in transporting contaminants to the groundwater. Vulnerability index was computed using Equation 1, as a weighted sum of the product of the rating and the weight multiplier.

$$
D_{i}=D_{r} D_{w}+R_{r} R_{w}+A_{r} A_{w}+S_{r} S_{w}+T_{r} T_{w}+I_{r} I_{w}+C_{r} C_{w}
$$

Where:

$D_{r} D_{w}=$ Rating and weight assigned to the depth to water table

$R_{r} R_{w}=$ Rating and weight assigned to the ranges of aquifer recharge

$A_{r} A_{w}=$ Rating and weight assigned to the aquifer media

$S_{r} S_{w}=$ Rating and weight assigned to the soil media

$T_{r} T_{w}=$ Rating and weight assigned to the topography (slope)

$I_{r} I_{w}=$ Rating and weight assigned to the vadose zone

$C_{r} C_{w}=$ Rating and weight assigned to the hydraulic conductivities

The final result is presented as numerical values. A high numerical value is assumed to be indicative of a geographic area that is susceptible to groundwater vulnerability. The higher the DRASTIC 
Index value, the greater the potential for groundwater pollution. The spatial distribution of the computed vulnerability index values constitutes the vulnerability map, which was subsequently reclassified to reflect spatial distribution of low, medium and high groundwater vulnerability. The land use map for the study area was used to identify anthropogenic activities that constituted potential pollution source, where there is high probability of pollution incident to occur due to prevailing surface anthropogenic activities within the study area. The land use map was superimposed on the reclassified vulnerability map, and areas where potential pollution sources on the land use map juxtapose with the areas identified as susceptible on the vulnerability map were delineated as areas prone to risk.

\section{Results and Discussions DRASTIC input layers}

The spatial data on the geology, soil, land use, topography, groundwater level and hydraulic conductivity are shown in Figure $2(\mathrm{a}-\mathrm{f}$ ). The generalized geology of the study area (Figure 2a) consists of Coastal Plain Sands and Alluvia deposits. The aquifer media describes the underlying geology which serves as storage for groundwater. According to Asiwaju-Bello and Oladeji (2001), there exist lateral lithological variation within the study area, and the aquifer thickens from its outcrop area in the north to the coast in the south. Also, the sand percentage in the formation increases from north to south (Adepelumi et al., 2009). In general, the larger the grain size, the higher the porosity and permeability become, and consequently the lower the attenuation capacity and the greater the vulnerability potential.

Soil media is the uppermost part of the ground, and its grain size, clay content and dispersion characteristics largely influence the infiltration and percolation of recharge and contaminants. The predominant soil types across the study area are Nitosols and Regosols, and their distribution are presented in Figure 2b. Factors such as climate, geology, geomorphology and hydrology may have influenced the distribution and composition of the soils within the study area. The topography describes the degree of slope within the area of study (Figure 2d). The landscape is generally dominated by low elevation, ranging from approximately $1.5 \mathrm{~m}$ amsl in the southern part to approximately $60 \mathrm{~m}$ amsl in the northern part of the area. According to Adepelumi et al. (2009), the surface elevation is greatly influenced by the underlying geology. Higher infiltration rate and contaminant percolation is likely to be associated with the areas having low elevation, and this consequently indicates vulnerability of the underlying groundwater resources. Regions of consistently low topography are potentially vulnerable as water can pool and infiltrate into the subsurface in these areas. Conversely, areas with steep gradient are likely to be characterized by large runoff and low infiltration rates, and consequently have lower vulnerability potential for the underlying groundwater resources. The groundwater map (Figure 2e) indicates very shallow depth, with less than $1 \mathrm{~m}$ in several places at the central and southwest patches compared to that obtained at the northeast patch, with a maximum depth of approximately $20 \mathrm{~m}$ below ground level. The depth to water indicates the thickness and travel time for infiltration through the unsaturated zone, and consequently the degree of interaction between the percolating contaminant and subsurface environment. It also impacts on the degree and extent of physical and chemical attenuation, as well as the degradation processes. Generally, the extent of protection of underlying water resources is largely dependent on the depth of water occurrence below the ground level.

Net recharge constitutes a significant factor in the consideration of contaminant transport within the subsurface environment. Generally, there is dearth of data on net recharge within the study area, and hence in this work a representative literature value of $84 \mathrm{~mm} /$ year obtained for the same area (Oladeji and Oyediran, 2020) was adopted. Impact of vadose zone characterizes the effects of the unsaturated zone on the infiltrating contaminants, and this is largely determined by its permeability 
and the attenuation characteristics. Information on the vadose zones was extracted from the borehole logs. Also, hydraulic conductivity is a measure of the capability to transmit water by geologic materials, and its spatial variation within the study area is shown in Figure 2f. Generally, the higher the hydraulic conductivity, the higher the vulnerability potential for the underlying water resources.

\section{Groundwater vulnerability and risk assessment}

The vulnerability index map based on the cumulated sum of the DRASTIC model input parameters is presented in Figure 3a. The higher the DRASTIC Index, the greater the groundwater vulnerability potential becomes. Hence, it was possible to reclassify the vulnerability map to identify areas which are more likely to be susceptible to groundwater contamination relative to others.

The re-classified version of the map that reflected the spatial distribution of low, medium and high groundwater vulnerability, with corresponding ranges of DRASTIC index values of $150-170,170$ - 190 and $190-210$, respectively, is presented in Figure 3b. Typical land use activities within the study area are presented in Figure 2c. The study area is generally described as urban, covering Lagos metropolis and the neighbouring settlements. Land use activities within the area of study are classified into Low, Medium and High risk based on their qualitative probable potential impacts on the subsurface environment. The potential risk posed to the underlying groundwater resources was qualitatively assessed and the results presented in Figures $3 c-3 d$.

The percentage distribution of the risk classification is presented in Figure 4, and it shows that $1 \%$ of the study area is designated as High-Vulnerability-High-Risk (HVHR) area. High-VulnerabilityMedium-Risk (HVMR) and Medium-Vulnerability-High-Risk (MVHR) constitute $3 \%$ each of the area, while $16 \%$ and $25 \%$ of the area are designated as Medium-Vulnerability-Medium-Risk (MVMR) and Low-Vulnerability-Medium-Risk (LVMR), respectively. Although, the total area designated as high and medium vulnerability constitutes approximately $75 \%$, dearth of risk activities in approximately $52 \%$ of this area suggests no risk is posed to the underlying groundwater resource within this subarea. Ojuri and Bankole (2013) delineated Lagos metropolis into seven zones of varying vulnerability using DRASTIC model, while Majolagbe et. al., (2016) characterized groundwater vulnerability index around Lagos Olososun dumpsite into two zones with $45 \%$ as moderate and 55\% high zones. However, the actual risk posed to the groundwater resources was not evaluated by the authors. 
Applying a GIS based DRASTIC Model in the Assessment of Risk to Groundwater Resources Within the Underlying Aquifers in Part of Lagos State, Nigeria

Table 1: DRASTIC index values

\begin{tabular}{|c|c|c|c|c|c|c|c|c|c|c|c|}
\hline $\begin{array}{c}\text { Data type / } \\
\text { Ranges }\end{array}$ & Rating & $\begin{array}{l}\text { Weight } \\
\text { Multiplier }\end{array}$ & Index & $\begin{array}{c}\text { Data } \\
\text { type / } \\
\text { Ranges }\end{array}$ & Rating & $\begin{array}{l}\text { Weight } \\
\text { Multiplier }\end{array}$ & Index & Data type / Ranges & Rating & $\begin{array}{l}\text { Weight } \\
\text { Multiplier }\end{array}$ & Index \\
\hline \multicolumn{4}{|c|}{ Depth to water table (m) } & \multicolumn{4}{|c|}{ Net Recharge (mm) } & \multicolumn{4}{|c|}{ Aquifer Media } \\
\hline $0-5$ & 10 & \multirow{6}{*}{5} & 50 & $0-2$ & 1 & \multirow{6}{*}{4} & 4 & Massive shale (1) & 2 & \multirow{6}{*}{3} & 6 \\
\hline $5-15$ & 9 & & 45 & $2-4$ & 3 & & 12 & Weathered Basement Rocks & 5 & & 15 \\
\hline $15-30$ & 7 & & 35 & $4-7$ & 6 & & 24 & Bedded Shale Sequence & 6 & & 18 \\
\hline $30-50$ & 5 & & 25 & $7-10$ & 8 & & 32 & Massive Sandstone & 8 & & 24 \\
\hline $50-75$ & 3 & & 15 & $10+$ & 9 & & 36 & Gravel & 10 & & 30 \\
\hline $75+$ & 2 & & 10 & & & & & Sand & 9 & & 27 \\
\hline \multicolumn{4}{|c|}{ Soil Media } & \multicolumn{4}{|c|}{ Topography } & \multicolumn{4}{|c|}{ Impact of Vadose Zone } \\
\hline $\begin{array}{l}\text { Sandy } \\
\text { loam }\end{array}$ & 6 & \multirow{5}{*}{2} & & $0-2$ & 10 & & & Silt / Clay & 3 & & 15 \\
\hline Loam & 5 & & & $2-6$ & 9 & & & Shale & 3 & & 15 \\
\hline Silty loam & 4 & & & $6-12$ & 5 & 1 & & Sand and Gravel with Clay & 6 & 5 & 30 \\
\hline $\begin{array}{l}\text { Clay } \\
\text { Loam }\end{array}$ & 3 & & & $12-18$ & & & & Sand and Gravel & 6 & & 30 \\
\hline Clay & 1 & & & $18+$ & & & & Karst Limestone & 8 & & 40 \\
\hline \multicolumn{4}{|c|}{ Hydraulic Condictivity m/day) } & & & & & & & & \\
\hline $1-100$ & 1 & \multirow{6}{*}{3} & 3 & & & & & & & & \\
\hline $100-300$ & 2 & & 6 & & & & & & & & \\
\hline $300-700$ & 4 & & 12 & & & & & & & & \\
\hline $700-1000$ & 6 & & 18 & & & & & & & & \\
\hline $1000-2000$ & 8 & & 24 & & & & & & & & \\
\hline $2000+$ & 10 & & 30 & & & & & & & & \\
\hline
\end{tabular}

Source: Ojuri and Bankole (2013) 




Figure 2: Geo-hydrologic layers for the DRASTIC model 


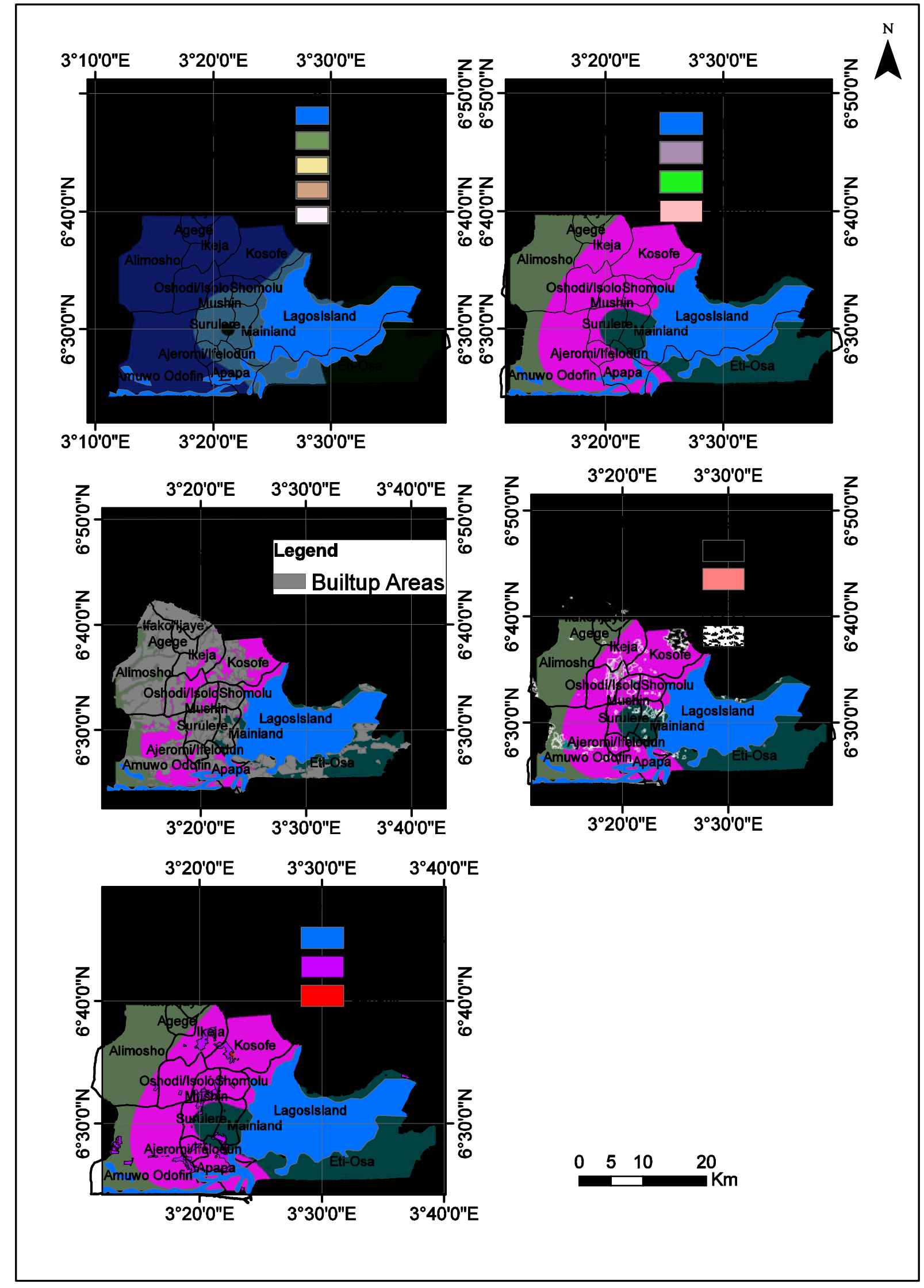

Figure 3: Vulnerability and risk maps 


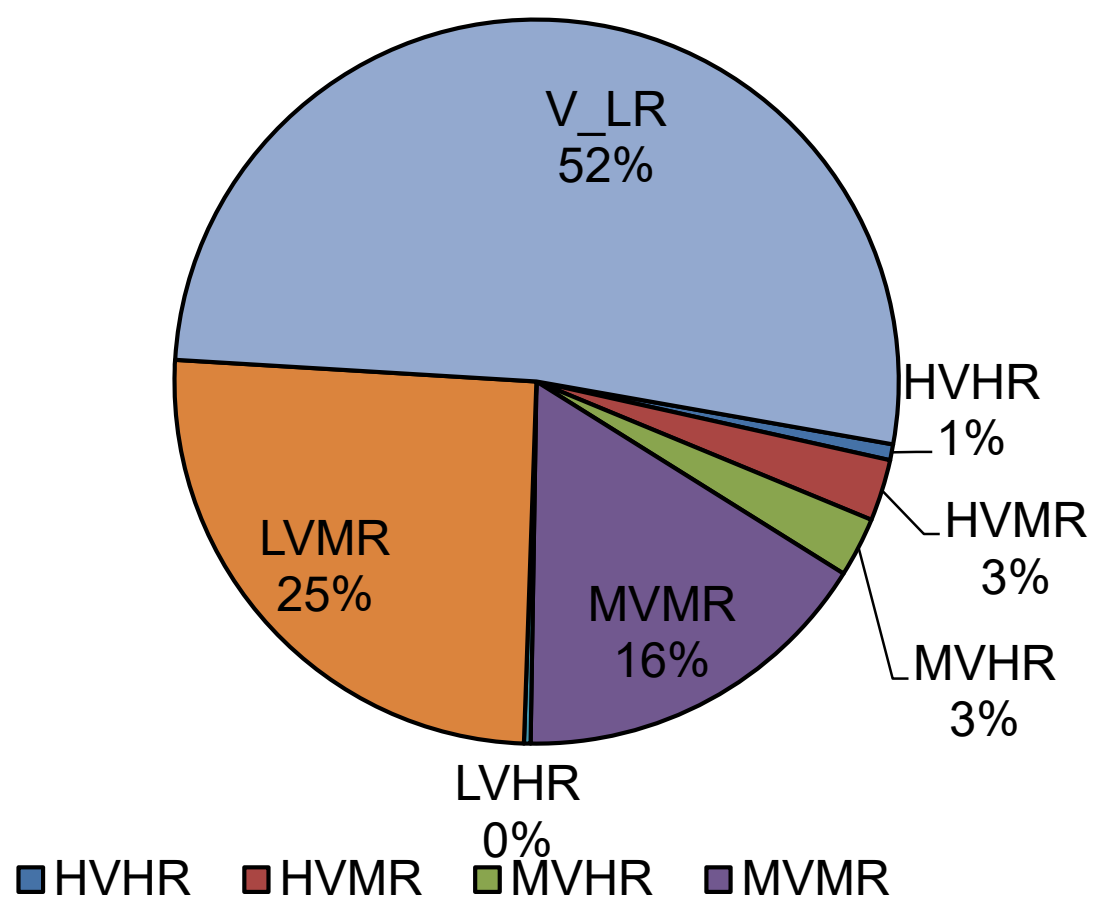

Note:

HVHR: High Vulnerability and Low Risk; HVMR: High Vulnerability and Medium Risk; MVHR: Medium Vulnerability and High Risk; MVMR: Medium Vulnerability and Medium Risk; LVHR: Low Vulnerability and High Risk; LVMR: Low Vulnerability and Medium Risk; V_LR: Vulnerability and Low Risk

Figure 4: Percentage risk distribution within the study area

\section{Conclusions}

In this study, anthropogenic induced risks posed to water resources within the underlying aquifers in Lagos State, Nigeria, was evaluated using qualitative DRASTIC modelling approach. This work was facilitated due to the need to assess risk posed to underlying groundwater resources caused by increased pressure induced by population growth. The acquired geo-hydrological data used for site characterization and setting up of the DRASTIC model include static water level, rainfall intensity, geologic data, soil data, ground surface elevation, borehole logs and pumping test data. These data were subsequently converted into grid and interpolated within the ArcGIS 10.1 software environment using appropriate extensions to obtain raster data for each of the input DRASTIC parameters. Vulnerability map was developed by summing the DRASTIC index values of the model input parameters and re-classified to reflect spatial distribution of Low, Medium and High groundwater vulnerability. Land use activities within the study area were also classified and superimposed on the vulnerability map to develop a risk map for the area. The results show that $1 \%$ of the study area is designated as High-Vulnerability-High-Risk (HVHR). High-VulnerabilityMedium-Risk (HVMR) and Medium-Vulnerability-High-Risk (MVHR) constitute $3 \%$ each of the area, while $16 \%$ and $25 \%$ were designated as Medium-Vulnerability-Medium-Risk (MVMR) and Low-Vulnerability-Medium-Risk (LVMR), respectively. Although, the total area designated as high and medium vulnerability constitutes approximately $75 \%$, dearth of risk activities in approximately $52 \%$ suggests no risk is posed to the underlying groundwater resource within the subarea. 


\section{References}

Aderibigbe, S. A., Awoyemi, A. O. and Osagbemi, G. K., (2008). Availability, adequacy and quality of water supply in Ilorin metropolis, Nigeria. Eur.J. Scientific Res. 23: 528-536.

Adelakun, I. O., (2009). Vulnerability of poor urban coastal communities to climate change in Lagos, Nigeria, Fifth Urban Research Symposium, (2009). In: Oyegoke, S. O., Adeyemi, A. O. and Sojobi A. O., (2012). The challenges of water supply for a megacity: A case study of Lagos metropolis. International Journal of Scientific and Engineering Research; 3 (2): 563 572.

Adepelumi, A. A., Ako, B. D., Ajayi, T. R., Afolabi, O. and Omotoso, E. J., (2009). Delineation of saltwater intrusion into the freshwater aquifer of Lekki Peninsula, Lagos, Nigeria. Environmental Geology. 56(5): 927-933.

Akiyode, O. O., (2010). Urban environmental security in developing economy megacity: A case study of Lagos, Nigeria. Journal of Sustainable Development in Africa. 12(5): 294-304.

Aina, T. A., Etta, F. E., and Obi, C. I., (1994). The search for sustainable urban development in Metropolitan Lagos, Nigeria: Prospects and problems. Third World Planning Review. 16: 201-219.

Aller, L., Bennett, T., Lehr, J. H., Petty, R. J., Hackett, G., (1985). Drastic: a standardized system for evaluating groundwater pollution potential using hydrographic settings. US-EPA Report 600/287-035.

Asiwaju-Bello, A. Y., and Oladeji, O. S., (2001). Numerical model of groundwater flow patterns within Lagos metropolis, Nigeria. Journal of Mining and Geology. 37 (2): 185-194.

Ayeni, A.O., Balogun, I. I., and Soneye, A.S., (2011). Seasonal assessment of physico-chemical concentration of polluted urban river: A case of Ala River in Southwestern Nigeria. Research Journal of Environmental Science. 5(1): 22-33.

Doerfliger N, Zwahlen F (1995) EPIK: a new method for outlining of protection areas in karst environment. In: Günay G, Johnson I (eds) Proceedings 5th International symposium and field seminar on karst waters and environmental impacts. Antalya, Sep 1995, Balkema, Rotterdam, pp 117-123.

El-Naqa, A., (2004). Aquifer vulnerability assessment using the DRASTIC model at Russeifa landfill, northeast Jordan. J. Environ Geol. 47(1): 51 - 62.

Federal Environmental Protection Agency (FEPA), (1998). Present Water Quality Status in Nigeria. Federal Environmental Protection Agency, Lagos. 35-41.

Federal Government of Nigeria (FGN), (2007). Legal Notice on Publication of the 2006 Census Report. Federal Government of Nigeria official Gazette. 4(94): 1- 8.

Grey, D., and Sadoff, C., (2007). Sink or Swim? Water security for growth and development. Water Policy. 9: 545-571.

Ilesanmi, A.O., (2010). Urban Sustainability in the context of Lagos megacity, Journal of Geography and Regional Planning. 3(10): 240-252.

Longe, E.O., Malomo, S., and Olorunniwo, M.A., (1987). Hydrogeology of Lagos Metropolis. Journal of African Earth Science. 6 (3): 163-174.

Majolagbe, A. O., Adeyi, A. A., and Osibanjo, O., (2016). Vulnerability assessment of groundwater pollution in the vicinity of an active dumpsite (Olusosun), Lagos, Nigeria. Chemistry International. 2(4): $232-241$.

Morris, B. L.; Lawrence, A.R.L., Chilton, P.J.C., Adams, B., Calow, R.C., Klinck, B.A., (2003). Groundwater and its susceptibility to degradation: a global assessment of the problem and options for management. Early warning and assessment report series, 03-3. United Nations Environment Programme. 126pp.

Odumosu, T., Balogun, Y. and Ojo, K., (Ed.) (1999). Lagos State in Maps, Rex Charles Publication, Ibadan, 1-50.

Ojuri, O. O., and Bankole, O. T., (2013). Groundwater vulnerability assessment and validation for 
a fast-growing city in Africa: A case study of Lagos, Nigeria. Journal of Environmental Protection. 4(5): $1-12$.

Oladeji, O and Elgy, J., (2012). Concepts and methods of quantitative assessment of risk to groundwater resources. International journal of environmental engineering and management. 3 (3): 159-171.

Oladeji, O. S., and Elgy, J., (2013). Characterization of potential pollution sources in the quantitative assessment of risk to groundwater resources within the Birmingham aquifers, UK. International Journal of Modern Engineering Research. 3 (6): 3441-3448.

Oladeji, O. S., and Oyediran, O. S., (2020). Applying Hydrological Distributed Catchment Model in the Estimation of Groundwater Recharge for Underlying Aquifers in Lagos State, Nigeria. European Journal of Engineering Research and Science. In Press. ISSN: 2506-8016.

Pathak, D. R., Hiratsuka, A., Awata, I., Chen, L., (2009). Groundwater vulnerability assessment in shallow aquifer of Kathmandu Valley using GIS-based DRASTIC model. Environ Geol. 57: $1569-1578$.

PRB (Population Reference Bureau), (2013). World Population Factsheet". www.pbr.org. Population Reference Bureau.

Vrba, J., and Zaporožec, A., (1994). Guidebook on mapping groundwater vulnerability. International Association of Hydrogeologists. International contributions to hydrogeology v. 16. Hannover: H. Heise,. 131pp.

WHO (World Health Organisation), (2010). Water for Health; Guideline for drinking water quality, incorporating 1 st and 2 nd addenda to 3rd edition. Volume 1 recommendations. WHO Press, World Health Organization, 20 Avenue Appia, 1211 Geneva 27, Switzerland. 